\title{
Shifting of attentional focus within and about a visual display
}

\author{
CHARLES W. ERIKSEN and JAYSON M. WEBB \\ University of Illinois, Urbana-Champaign, Illinois
}

\begin{abstract}
If several positions must be attended in a large visual display, does the efficiency of performance vary as a function of the display distance between these to-be-attended positions? Two previous experiments (Podgorny \& Shepard, 1983; Shaw, 1978) gave conflicting answers. In the present experiments, eight-letter circular displays were briefly presented. On each trial one, two, or three positions of the display were cued or precued. The number of noncued display positions intervening between the cued locations varied from zero to three. The subjects' task was to rapidly discriminate between two target letters. Although reaction time was found to increase with increases in the number of cued locations, no significant or suggestive effects were found for the spacing or distance between the cued locations. The evidence strongly suggests that the subjects serially searched the cued locations, which further implies that attention can index locations in the visual field at a speed that is independent of the distance between these locations.
\end{abstract}

If a subset of stimuli must be attended in a complex large visual display, does it matter which way this subset is distributed throughout the display and intermixed with distractor stimuli? Our purpose in the present experiments was to obtain some evidence on this question and to relate the findings to several current conceptions of visual attention. To preclude the role of saccadic eye movements, we dealt only with displays presented for durations too brief for changes in eye fixation.

Although there is a vast literature on visual search, only a few studies have addressed the question we have posed above. Two of these studies came up with conflicting answers (Podgorny \& Shepard, 1983; Shaw, 1978; Shaw \& Shaw, 1977). The visual display used in Podgorny and Shepard's (1983) experiment was a $3 \times 3$ matrix of squares. Prior to a trial, a subject was instructed to distribute his/her attention over a subset of these squares. The squares to be attended were lightly shaded. When the subject felt that his/her attention was deployed over the lightly shaded area, he/she initiated the trial. At this point a dot appeared in one of the nine squares. The subject made a discriminated response as to whether the dot occurred on a shaded or a nonshaded square, and the latency of the response was recorded. Latencies were shortest when the target fell on attended squares. Furthermore, the latencies were reduced when the subregion of shaded squares (attended) constituted a compact region on the nine-square display. Latencies increased as attended squares were distributed over the display with nonattended squares intervening between attended ones.

This research was supported by Public Health Service Research Career Program Award K6-MH-22014 to the first author and by United States Public Health Service Research Grant MH-012006, also to the first author. Requests for reprints should be sent to Charles W. Eriksen, Department of Psychology, University of Illinois, Urbana-Champaign, 603 East Daniel, Champaign, IL 61820.
Crassini (1986), in a reanalysis of Podgorny and Shepard's (1983) data, concluded that a benefit in responding occurred only when the attended squares were unitary, that is, when the attended squares were not separated or interlarded with squares that were not to be attended (see Shepard \& Podgorny, 1986).

The results of these experiments suggest that attention can be distributed over subareas of a visual display and, furthermore, that difficulty in this distribution of attention occurs if the to-be-attended area is not compact, or perhaps unitary. However, these results can be considered only suggestive. The experiments provided no control for eye fixation. Thus possible attentional effects are confounded with retinal acuity since it is very likely that the subjects varied their eye fixations to correspond with the area of the display that was to be attended. Furthermore, since these data were averaged over trials and subjects, it is unclear whether attention was actually uniformly distributed over the shaded squares on a single trial. An average response time (RT) advantage for the shaded squares would have been obtained if only a subset or even only one of the shaded squares was attended on each trial and this square or subset varied over trials within and between subjects.

The results of the Shaw and Shaw (1977) and Shaw (1978) experiments are at variance with the findings of Podgorny and Shepard (1983). Shaw (1978) used a twochoice RT task with visual displays containing one target letter and five distractor letters. Although the question of the distribution of to-be-attended areas throughout the display was not specifically addressed by Shaw, the data from her experiment bear directly on this question. Prior to each trial, different display locations were assigned different probabilities of target occurrence. The variation of these locations in the display covered a range that varied from compact to well distributed. The assignment of different 
probabilities of target occurrence to different display locations was a manipulation designed to control attentional deployment in the display. Shaw's model conceives of visual attention as consisting of a fixed amount of resources that can be allocated to different display locations on a trial in amounts corresponding to the probability of a target occurring in that location.

Both the accuracy (Shaw \& Shaw, 1977) and the latency (Shaw, 1978) of the discriminated response were found to correspond with the a priori probability of the target occurrence. However, there was no indication that the results were dependent upon the particular locations or proximities of high-probability target locations throughout the display.

Shaw's (1978) model does not specifically address the issue of the effect of compactness of the to-be-attended display areas. However, as formulated, the model does suggest that compactness or unitariness of the to-beattended areas would not be a factor in determining the effectiveness of attentional allocation. Attention can be allocated to discrete areas of the display, and processing of stimuli in these locations would proceed in parallel, but at different rates if the allocation of resources to the different positions was unequal. However, as with Podgorny and Shepard's (1983) experiments, the data are less than conclusive as to whether or not attention was actually deployed on several separated locations on each trial. Average RTs over trials could give the appearance of deployment due to subjects' matching over trials the location of a unitary attentional focus to the a priori probabilities of target occurrence.

Late-selection models of attention, such as those of Duncan (1980) and Hoffman (1979), appear to offer no basis for an expectation that the distribution of high-probability target locations would affect performance. These models are distinguished by positing a large-capacity parallelprocessing preattentive stage in which stimuli are processed to the point of identification (Duncan, 1980). On the basis of the discriminations and identifications occurring in the preattentive stage, stimuli are selected for serial entry into short-term memory, consciousness, and access to responses. Applied to our problem of the distribution of designated locations in a complex display, late-selection theories would not expect distribution to make a difference since all locations are parallel-processed. There might be a gain by restricting the target to subregions of a display in that these regions or locations might constitute a discriminative cue that would therefore expedite the processing of the stimuli in these locations. Again, however, since this subset of locations would be processed in parallel, there is no reason to expect their adjacency or separation to affect the efficiency with which they are processed.

Eriksen and Yeh (1985) and Eriksen and St. James (1986) proposed a zoom lens model of the visual attentional field. In this conception, the attentional field can vary in size from approximately a degree of angle to a size that encompasses the entire effective visual field. Like a zoom lens, as the size of the field varies, there is a reciprocal variation in the resolving power for detail. When attention is directed to a specific stimulus, the attentional field effectively zooms in on the stimulus, increasing resource density and decreasing field size until the resource concentration is sufficient to make the required discrimination or extraction of detail and information.

Although the model is not specific as to the shape that the attentional field can assume, the initial assumption is that the field is unitary, that is, that attentional resources are uniformly distributed over the field. Thus if two stimuli located $6^{\circ}$ of angle apart are to be simultaneously attended, the attentional field must be enlarged to at least $6^{\circ}$ to encompass both stimuli. In this instance there will be fewer resources for processing each of the stimuli than if the stimuli had been only $2^{\circ}$ apart. In the former case the density of resources on a given location in the attentional field will be lower. This lower density may be adequate to make the necessary discrimination if the discrimination requirement is not high (e.g., between $X$ and $O$ ), but the assumption is that the discrimination will be slower than if the resource density had been higher. There will be cases in which the resource density in a large attentional field is not sufficient to extract the necessary information from the stimuli to make a discrimination. In this case the attentional field is presumed to zoom in on one stimulus and then the other, processing each in turn.

Eriksen and St. James (1986) used circular displays of eight letters and cued or precued one, two, or three adjacent locations. Two-choice RT was employed, and a target letter occurred in only one of the cued locations. Mean RT increased as the number of cued locations increased. Supplemental analyses and experimental operations strongly indicated that the cued locations were processed or searched in parallel rather than serially. This was consistent with the conclusion that the attentional focus or field enlarged or contracted with variation in the number of cued locations. The data strongly indicated that when the number of cued locations approached half of the display area, subjects tended to abandon processing the cued area alone and, instead, enlarged the attentional field to include the entire display. (The experiments of Eriksen \& Yeh, 1985, and Jonides, 1983, also indicated that subjects had these processing options.) This strategy was effective since the discrimination involved in the experiments was between $S$ and $C$, with distractor letters that were composed of straight lines and angles, such as $\mathbf{N}$ and $\mathrm{W}$.

In Eriksen and St. James's (1986) experiments, the cued locations were always contiguous, and thus the attentional field could remain unitary even when enlarged to include three locations. Inasmuch as RT increased with increases in cued area, interspersing cued locations with noncued positions containing noise or distractor stimuli would be presumed to decrease the density of processing resources to the point that they were insufficient to perform the task. This would be particularly likely if the discrimination task 
was made difficult. At some point, we would anticipate that the attentional field would zoom in to focus on only one position at a time, and thus processing would become serial.

The above models are not exhaustive in terms of different ways of conceptualizing visual attention. Nonetheless, they are representative of three classes of models and embody most of the distinguishing characteristics that are relevant to our present problem. Shaw's (1978) model provides for a dividing of attention in the visual field by allocating different amounts of resources to the separate locations. Late-selection models with parallel processing of all the stimuli in the preattentive stage, like Shaw's model, would not predict a differential effect of location distribution on processing efficiency. However, both models would predict that the greater the number of these to-be-attended locations, the poorer the performance. In the case of Shaw's model, this would be attributable to the dividing of a limited amount of resources among the different locations. Late-selection theories, on the other hand, would attribute a decrease in performance with an increase in number of to-be-attended locations to an increased probability of confusion errors and the necessity for a higher response criterion.

The zoom lens model, as well as variable-size spotlight models (LaBerge, 1983), makes a rather clear prediction that performance would be impaired if the to-be-attended areas are distributed throughout the display and interspersed with distractor stimuli. For the attentional field to enlarge to include all to-be-attended locations, resources would have to be distributed over nondesignated locations as well, in order to keep the attentional field unitary. Thus processing resources would be thinly distributed and wasted on nondesignated locations.

Both the zoom lens and variable-size spotlight models provide for a serial search approach to the multilocations task. If a distributed attentional field is unable to efficiently handle the discrimination, the spotlight can narrow or the attentional field can zoom in to concentrate resources on one location at a time. The time required for serial search will, of course, increase with increases in the number of designated locations. The effect of distance between these locations will depend upon whether attention moves in an analogue fashion across the visual display. Although some studies have concluded that attention does move in such an analogue manner (Shulman, Remington, \& McLean, 1979; Tsal, 1983), questions have been raised as to the adequacy of their evidence (Eriksen \& Murphy, 1987). More recent studies (Murphy \& Eriksen, 1987; Sagi \& Julesz, 1985) have concluded that attention indexes locations in the visual field at a speed that is independent of the distance of the initial starting point.

In the present experiments, we used a two-choice RT task to investigate the effect upon RT of the number and compactness of to-be-attended positions in a visual display. The displays consisted of one target letter and seven noise letters equally spaced in a circular arrangement. The attended locations were a subset of one to three of the eight display positions, and the subset was designated by underlines. The compactness of these designated locations was varied by the number of display positions that intervened between the underlined positions.

\section{EXPERIMENT 1}

\section{Method}

Subjects. Six women and 4 men, students at the University of Illinois, Urbana-Champaign, served as paid subjects. All were righthanded and had normal or corrected-to-normal vision (by selfreport).

Apparatus. Stimuli were presented on a Panasonic Matrox video display. Viewing was binocular at $97 \mathrm{~cm}$, and luminance was $37 \mathrm{fL}$ as measured by a Spectra Brightness Spotmeter. Letters were approximately $.3^{\circ}$ of angle in height. Stimulus presentation and RT recording were controlled by a program using routines from the PEARL-II Subroutine Library developed at the University of Illinois. The program was run on an RT-11 computer.

Design and Procedure. The subject's task was to discriminate between the letters $\mathrm{Y}$ and $\mathrm{N}$ as quickly as possible. On each trial, one of these target letters was presented with seven other letters (noise) in a circular display that was $2^{\circ}$ of visual angle in diameter. The eight positions were equally spaced on the circumference and were $.78^{\circ}$ of angle apart. The target letter was indicated by an underline cue. During a block of 32 trials, each target letter occurred twice in each of the eight possible display locations. The noise letter set was $K, V$, and $H$. Two of these noise letters appeared twice in each display, and one appeared three times.

Three within-subject variables were manipulated. The first variable was the number of display locations that were cued on a trial: one, two, or three locations were cued by a horizontal line that was the same width as the target letter. It underlined the display position. When two locations were cued, one was a target and the other was noise. The location of the target relative to the cued noise was counterbalanced; that is, the noise location was equally often clockwise and counterclockwise from the target location. When three locations were cued, one location was the target and the other two were noise. The relative location of the target to the cued noise was counterbalanced, with the target appearing equally often as the left, middle, or right of the three positions cued. Each of the noise letters was cued equally often in a block of trials for both the twoand three-positions cued conditions.

The second variable was the stimulus onset asynchrony (SOA) by which the cues preceded display onset. The values of SOA were 0 and $175 \mathrm{msec}$. For SOA $=0$, the cue(s) appeared on the video display simultaneously with the array of letters. For SOA $=175$, the cue(s) appeared on the video display $175 \mathrm{msec}$ prior to the array of letters. Prior research (Colegate, Hoffman, \& Eriksen, 1973; Eriksen \& Hoffman, 1972; Jonides, 1980, 1983; Tsal, 1983) has shown that a precue $175 \mathrm{msec}$ in advance of the display is sufficient to permit focusing of attention on the cued position.

The third variable was the distance between cued locations. This variable had no value when only one position was cued. When two positions were cued, the value of the distance variable ranged from 0 to 3 . The two locations cued were contiguous (2-0), separated by one display location containing a noise letter (2-1), separated by two display locations containing noise (2-2), or separated by three locations containing noise (2-3). When three positions were cued, the value of the distance variable was either 0 or 1 . The three locations cued were contiguous (3-0) or separated by a noise letter (3-1). Figure 1 illustrates a two-position cued display in which cued positions are separated by a noise letter $(2-1)$. The number of locations cued and the distance variable were crossed to create a blocking factor with seven values.

Trials were blocked by cue type and SOA. The subjects participated in three sessions. Session 1 was a practice session in which all 14 blocks of trials (cue type $\times$ SOA) were presented to famil- 


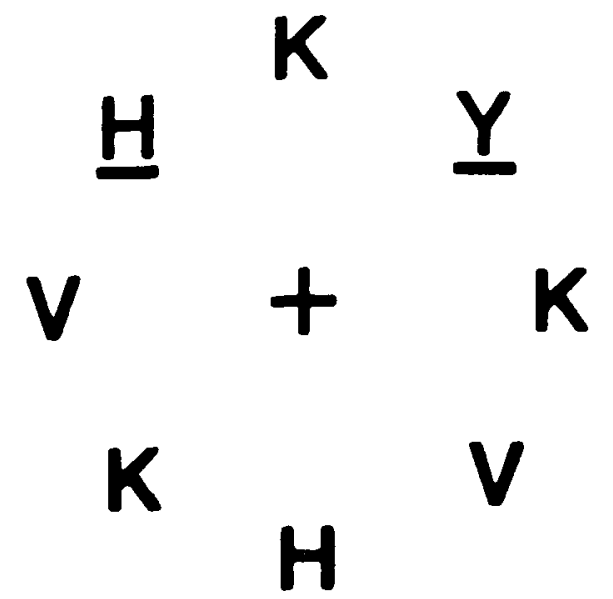

Figure 1. Ilustrations of a stimulus display in which two positions are cued, separated by a noise letter. The target is the $Y$ in the upper right quadrant.

iarize subjects with the task. During the two following experimental sessions, the subjects performed each of the 14 blocks of trials twice. A block of trials consisted of 32 presentations of the circular display of letters. The subjects initiated a trial by pressing a foot pedal in response to a fixation cross centered on the video display. In the 0-msec-precue condition, the circle of letters with positions cued appeared on the video display $1 \mathrm{sec}$ after the foot pedal was pressed. In the 175 -msec-precue condition, the cues appeared $1 \mathrm{sec}$ after the foot pedal was pressed. The cues appeared along the circle where the letters would appear and remained alone on the screen for $175 \mathrm{msec}$, after which the circular array of letters was superimposed on the display. The circular array with underlines remained on the screen for $50 \mathrm{msec}$.

The subjects were instructed prior to the experimental session to respond by pressing a lever either left or right if one of the cued letters was an $\mathrm{N}$ and the other direction if it was a $\mathrm{Y}$. The subjects were instructed to make their responses as quickly as possible while maintaining accuracy. After making a response, the subjects were provided with feedback concerning their accuracy and RT on that trial. At the end of a block of trials, the average RT for correct trials and the total number of correct responses were displayed on the subject's video display. The subjects began each experimental session by performing the one-position-cue condition with either the 0- or 175-msec precue. This block of trials was presented first to orient the subject to the task. It was not used in the RT analysis. The second block was the other one-position-cue condition ( 0 - or 175-msec SOA). The subsequent blocks, 3 through 14, presented the remaining conditions in a random order. If the subject started with the one-position-cue condition with $\mathrm{SOA}=0$ for Experimental Session 1, he/she started with the one-position-cue condition at 175-msec SOA for Experimental Session 2.

\section{Results}

The data were first examined for the effect of number of cued or designated locations and SOA. For this analysis the data for two and three designated locations were collapsed across the spacing variable. A within-subjects analysis of variance (ANOVA) was performed on the response latencies. Highly significant effects were obtained for SOA $[F(1,9)=51.7, p<.001]$ and for the number of locations that were designated $[F(2,18)=54$, $p<.001]$. The interaction between SOA and the number of cued locations was also significant $[F(2,18)=4.72$, $p<.03$ ]. The nature of these effects can be seen in Figure 2, where mean response latency averaged over subjects is shown as a function of the number of cued locations. Separate functions are shown for the 0 - and 175msec SOAs.

Response latency increased as a negatively accelerated function as the number of designated locations increased from one to three. The effect is quite comparable to what Eriksen and St. James (1986) obtained. The effect of precuing the designated positions $175 \mathrm{msec}$ before onset of the letter display is also quite comparable to previously obtained effects (Eriksen \& St. James, 1986; Eriksen \& Yeh, 1985; Jonides, 1980). Latency is appreciably shorter for one, two, or three designated positions if these positions are indicated in advance. However, the effect of precuing is greatest when only one position is designated. The effect becomes progressively lower as the number of designated locations increases. This is the basis of the interaction between number of designated locations and SOA that was noted above.

Our main interest in this experiment was the effect of spacing between designated locations. In Figure 3 response latency is shown as a function of the distance or spacing between cued locations when two and three locations are designated. Again, the data are plotted separately by SOA.

It is quite evident from inspection of the figure that the spacing between designated locations shows no systematic effect for either two or three cued or precued positions. These observations are supported by statistical tests. The four different spacings or distances in the twoposition-cue condition and the two spacings in the three-position-cue condition were evaluated in separate ANOVAs (SOAs $\times$ spacing $\times$ subjects). In neither anal-

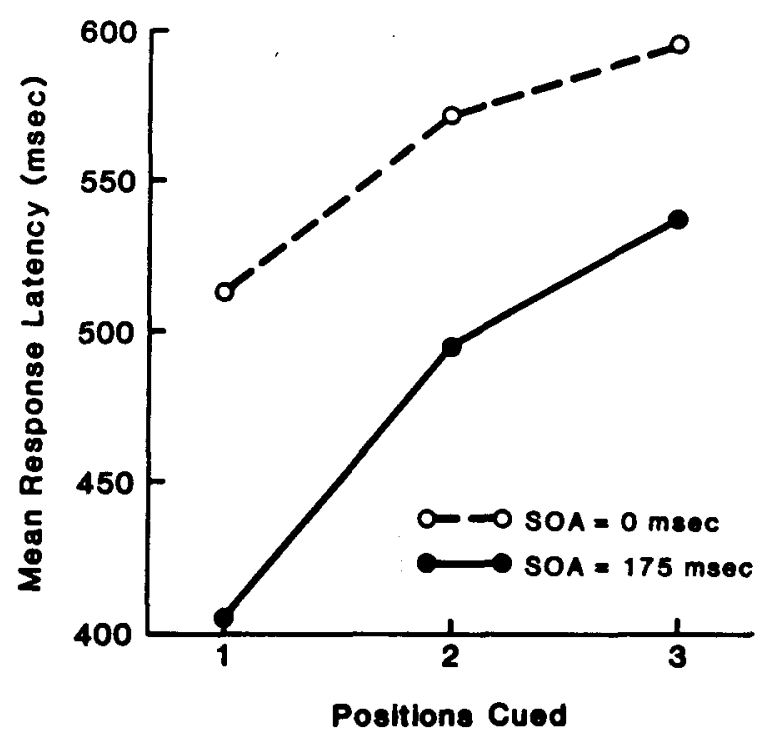

Figure 2. Mean response latency (in msec) as a function of the number of cued positions. Data were collapsed over the spacing variahle. Separate functions are shown for when the cues occurred simultaneously with the display (SOA $=0 \mathrm{msec}$ ) and when the cues preceded the display $(\mathrm{SOA}=175 \mathrm{msec})$. 
ysis did spacing approach significance $(p>.3)$, and there was no suggestion of an interaction between spacing and SOA.

Figure 3 also shows the error rates for each spacing $x$ cuing condition. The errors for the two positions cued were analyzed in a repeated measures ANOVA for spacing and cuing condition (simultaneous vs. precuing). The cuing effect was significant $(p<.05)$, but there was no reliable effect for spacing $(p>.20)$; however, the interaction approached significance $(p<.20)$. The error rates in the simultaneous-cue condition were appreciably higher than with the 175 -msec precue. This corresponds with the differences observed in the RT measures and contraindicates a speed-accuracy trade-off. ${ }^{1}$

\section{Discussion}

The above results are quite clear in showing no facilitation in target identification as a function of the compactness (Podgorny \& Shepard, 1983) or the unitariness (Crassini, 1986) of the cued locations in the displays. With two cued locations, performance was as good when these locations were maximally separated in the display as when they were adjacent positions with no intervening noise letters. Essentially the same result was obtained when three locations were cued.

These results are consistent with a conclusion that attention can be simultaneously focused in several locations at once (Shaw, 1978) and that the distribution of these locations in the visual field does not impair or enhance the effectiveness of attention. They are also consistent, however, with a unitary focus of attention that serially processes each of the cued locations in turn until a target is identified. This interpretation, however, requires the attendant assumption that the attentional focus traverses visual space at a speed independent of the distance between cued locations, an assumption that is supported by recent evidence (Murphy \& Eriksen, 1987; Remington \& Pierce, 1984; Sagi \& Julesz, 1985).

Before we can draw conclusions regarding the operation of attention and the compactness of to-be-attended areas in the visual field, we need to ensure that focal attention or concentrated attentional resources were operating in the experimental task. Various experiments have found evidence of automatic or parallel processing of visual displays under certain conditions (e.g., Eriksen \& Spencer, 1969; Gardner, 1973; Kinchla, 1974; Schneider \& Shiffrin, 1977; Shiffrin \& Gardner, 1972; Treisman $\&$ Gelade, 1980). Some of these conditions are ease of discrimination, extensive practice under consistent mapping of targets and noise, and single-dimensional definition of targets. In the present experiment, although there was consistent mapping of the target and noise letters, there was relatively little practice. Furthermore, the discriminations between targets and between the targets and the noise letters were reasonably difficult. Nonetheless, the possibility that the entire display was searched in parallel must be entertained. For an automatic search, our results have no relation to the effect of compactness on the efficiency of processing with focal attention.

The present finding that response latency increased as the number of cued locations in the display increased suggests that the cuing of locations did affect the distribution of attention. However, this increase of latency could have resulted from an increase in discrimination difficulty, with a consequent raising of the response criterion. The underlining of letters in the displays as a means of cuing can also be considered to act as a distinctive feature. If the elements of the displays were processed preattentively

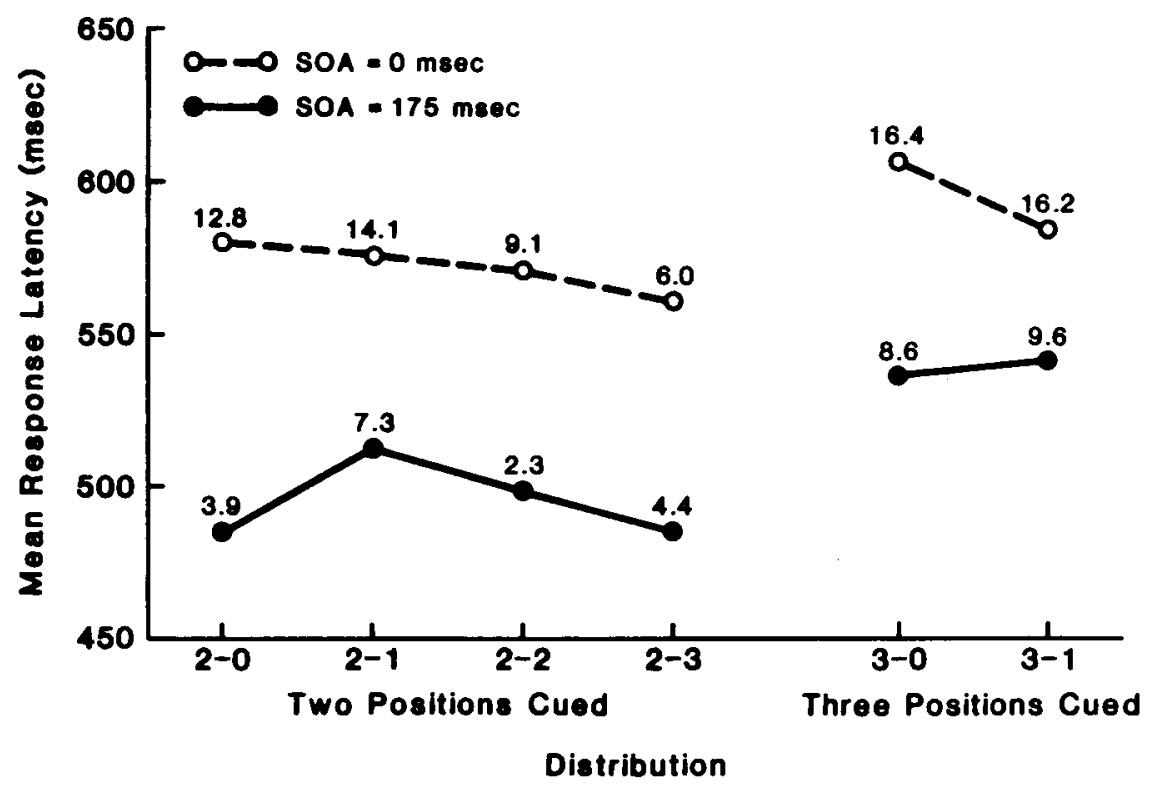

Figure 3. Mean response latency (in msec) as a function of the spacing between cued locations. Separate functions are shown for the two SOA values. Each point in the figure shows the associated error rate as a percentage of total trials. 
or in parallel, the underline would serve as a distinctive feature to facilitate the processing of the target. When two or more letters were underlined, the subject may have had to raise his/her response criterion due to the greater likelihood of confusions with the now greater number of similar letters. Essentially, we have a display-size effect upon RT that, as Townsend (1971) has shown, cannot by itself distinguish between serial and parallel models.

Stronger evidence that focal attention was being directed to the cued areas of the display is found in the effect of precuing. Precuing the possible target locations $175 \mathrm{msec}$ before display onset resulted in an appreciable reduction in latency whether the designated positions were one, two, or three in number and irrespective of whether they were adjacent or distributed throughout the display. The magnitude of the decrease in RT with precuing is quite comparable to what has been obtained in a number of other experiments with displays of comparable size (e.g., Eriksen \& St. James, 1986; Eriksen \& Yeh, 1985; Jonides, $1980,1983)$. Precuing the location results in the attentional focus being at the target location before target arrival, and thus processing of the target is expedited.

It is possible, however, that the precues occurring $175 \mathrm{msec}$ before display onset had a general alerting effect that primed responses in general rather than a facilitation effect for the cued locations. Other experiments (e.g., Eriksen \& Yeh, 1985; Jonides, 1980) have provided controls for possible general alerting effects and have found that the specific cuing of target location resulted in effects appreciably greater than could be attributed to a general priming. Since the effects found in the present experiment are considerably greater than those found for such first-signal effects and are of a magnitude obtained for attentional precuing, it seems unlikely that the present results can be attributed to a general alerting component. Nonetheless, a second experiment was performed to remove any residual doubt.

\section{EXPERIMENT 2}

This experiment used displays similar to those in the previous experiment. Only the condition in which two positions were cued was run. Again, the two cued locations could be adjacent (2-0), separated by one position containing a noise letter (2-1), separated by two positions containing noise letters (2-2), or separated by three noise letters (2-3). Instead of precuing both possible target positions in the display $175 \mathrm{msec}$ before display onset, one of the possible target locations was precued $50 \mathrm{msec}$ before the display. The remaining position was cued simultaneously with the display onset. If precuing was acting to focus attention on the possible target locations and the cued locations were searched serially, RTs should be significantly and appreciably shorter when the target occurred in the first cued position. If, however, the precues served only as a general alerting stimulus, then targets occurring in either position should be equally facilitated.

\section{Method}

Subjects. Five women and 5 men, students at the University of Illinois, Urbana-Champaign, served as paid subjects in three 1-h sessions.

Apparatus and Stimuli. The equipment was the same as in Experiment 1 . A change was made in the stimuli. The target letters were $H$ and $N$, and the noise letters were $M, W$, and $A$.

Procedure. Although the number of target locations was varied from one to three in the previous experiment, only the two-cuedlocations condition was run in the present experiment. The four distributions of these locations $(2-0,2-1,2-2$, and 2-3) were run separately in blocks of 32 trials. The first cue appeared as an underline of one of the display positions. The eight-letter display appeared $50 \mathrm{msec}$ later. Simultaneously with the appearance of the display, the second position was underlined. The display and both underlines terminated $150 \mathrm{msec}$ later. On half of the trials, the second underline or cued location was clockwise of the first cued location, except that in the 2-3 distribution, it was diametrically opposite. On half of the trials, the target occurred in the location that was cued $50 \mathrm{msec}$ before the display onset. The order of this occurrence was determined in a pseudo-random manner. The first session was practice, and it was followed by two sessions of eight trial blocks each.

\section{Results}

Mean correct RTs were determined for each subject for each cell of the experimental design. These mean latencies were analyzed in a within-subjects ANOVA. As in Experiment 1, there was no significant effect for the distribution of possible target locations $[F(3,27)=1.74$, $p>$.18]. The effect for whether the target occurred in the first or second cued location, however, was highly significant $[F(1,9)=57.14, p<.001]$. The interaction of these two variables did not approach significance $[F(3,27)=1.06, p>.30]$.

In Figure 4 the average RT to the target is shown for each of the four spacings for those trials in which the tar-

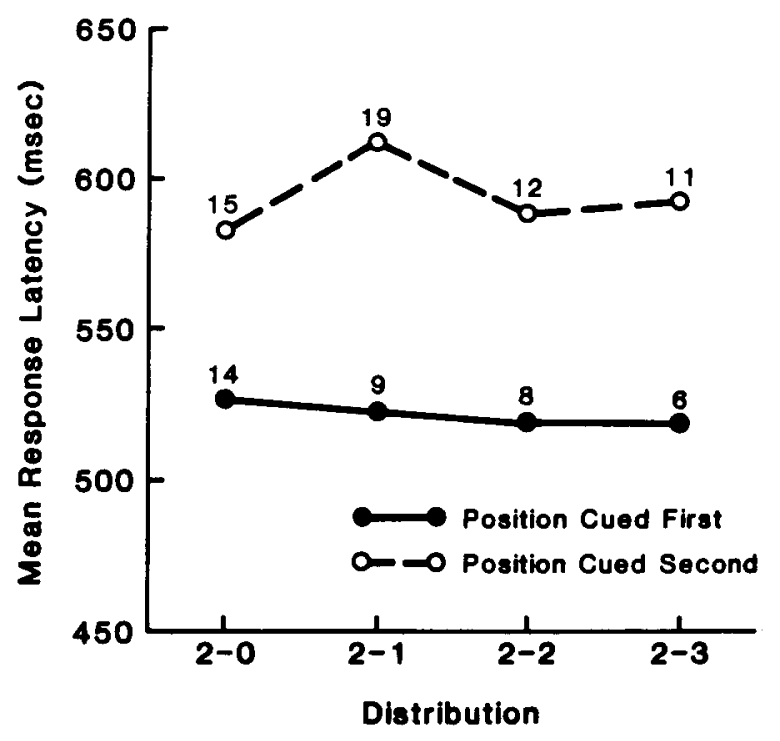

Figure 4. Mean response latency (in msec) as a function of the spacing between cued locations. Separate functions are shown for the two SOA values, and each point shows the associated error rate. 
get occurred in the first location and those trials in which the target was in the second location. As in Experiment 1, there is no suggestion that RT varied as a function of the spatial separation of the cued locations in the display. This is true, irrespective of whether the target occurred in the first or second cued location. However, there is a very pronounced reduction in RT if the target was located in the first cued location rather than the second. Averaged over the four separations, mean RT was $60 \mathrm{msec}$ faster when the target was in the position that was cued $50 \mathrm{msec}$ before display onset.

The finding that RT was appreciably faster when the target was in the first cued location is strong evidence that we are dealing with focal attention in these experiments. As in other experiments (e.g., Eriksen \& Hoffman, 1973; Eriksen \& Yeh, 1985; Jonides, 1980, 1983; Tsal, 1983) that have used precuing, the cue appears to direct or focus attention on the relevant areas of the visual field. The facilitation of performance that the precue produces cannot reasonably be attributed to an early warning or alerting effect from a signal that precedes the display. Such a general or a specific effect would be independent of whether the target appeared in the first or the second cued location. The error data that are also shown in Figure 4 were analyzed in a repeated measures ANOVA. As in Experiment 1 , the effect for precuing was significant $(p<.05)$, but there was no reliable effect for spacing and the interaction did not approach significance.

\section{GENERAL DISCUSSION}

The results from both Experiments 1 and 2 failed to provide any evidence that the effectiveness of predirecting attention to areas of the visual field depends upon how compact or unitary these areas are. These results are in conflict with the findings of Podgorny and Shepard's (1983) experiments, both in terms of their conclusion regarding the role of compactness and the stronger version of the conclusion arrived at by Crassini (1986) in a reanalysis of Podgorny and Shepard's data. Our conclusion is that the dispersion or separation of the to-beattended areas has no effect upon the benefits derived from predirecting attention. Although this conclusion is essentially based upon a negative result, our experiments have investigated a range of dispersion. Not only was there no suggestion of significant variation in RT among these dispersions, but no trend was discernible that RT varied as a function of distance between the cued locations.

The present result cannot be interpreted as a failure to replicate Podgorny and Shepard's (1983) results since there are too many differences in the task and the precuing procedures used in the two studies. Podgorny and Shepard allowed the subject to initiate a trial when he/she felt that attention was distributed on the designated locations. The task was to determine whether a dot appeared on a designated or nondesignated location, rather than form discrimination. As we noted in the introduction, Podgorny and Shepard's experiments provided no con- trol for eye fixation. It seems quite likely that subjects fixated something corresponding to a weighted center of the to-be-attended area. Thus a drop-off in performance for outliers would be expected due to a corresponding drop-off in retinal acuity. At best, their results are confounded with the acuity variable. We also noted that a subject's strategy of attending or fixating a smaller subset of the to-be-attended area, with the subset varying over trials, would produce averaged data that gave the illusion that subjects were indeed distributing attention over the entire designated locations.

The negative results that we obtained have saved lateselection models, such as those of Duncan (1980) and Hoffman (1979), and Shaw's (1978) early-selection model from embarrassment. As noted earlier, these models have no provision for accounting for distance or separation effects between stimuli to be attended or processed. Our failure to find separation effects does little, however, to help us choose between the many competing models of attention.

It is tempting to conclude serial processing of the designated locations based upon the results of Experiment 2. The 60-msec gain in RT when the target occurred in the location that was precued is well described by an interpretation that says that the precued location was processed first. When a target was not found in this location, attention was then directed to the second cued location. The 60-msec greater RT for targets in the second location arises from the time taken to process the letter in the first location far enough to determine that it was a noise letter and then to shift attention to the second location. If this serial processing could definitely be established, it would be evidence against Shaw's (1978) model. It would indicate that attentional resources were not simultaneously allocated to separated locations in the visual field.

The zoom lens model of Eriksen and Yeh (1985), on the other hand, is saved by the serial interpretation. In this model the attentional field can be enlarged to include all the designated locations, but only by including the intervening positions that contain noise letters. Thus the size of the attentional field increases as the separation between cued locations increases, with a consequent decrease in attentional resources available in each display location encompassed by the field. The model clearly predicts that RT should increase with increases in the separation between cued locations. The model can handle the present results by assuming that the difficulty of the discrimination between targets and between targets and noise made it advantageous to zoom attention down to the size of one display location. Then the cued locations were searched serially until a target was identified.

The present results, however, do not demand a serial processing of the designated locations. Shaw's (1978) model can explain the faster processing of targets that occur in the precued location of Experiment 2 by assuming that resources are allocated to this display location beginning with the onset of the precue. When the display occurs along with the second cue, further resources are 
allocated to the second cued location. The processing of both cued locations proceeds simultaneously, but on the average targets occurring in the first location will finish processing first due to the lead time advantage they have in resource allocation.

Nonetheless, we prefer a serial search interpretation of the present studies based upon evidence from other experiments. Eriksen and Yeh's (1985) experiments provided strong evidence that attention was not able to focus two cued locations simultaneously. Very similar displays were used in those experiments, and the $60-\mathrm{msec}$ faster RT found in the present Experiment 2 when the target occurred in the precued location is quite comparable to the 60-70 msec that Eriksen and Yeh estimated for processing a location, determining that it contained a noise letter, and then directing attention to the other cued location. This time value is also quite comparable to the search rate that Treisman and Gelade (1980) reported for searching for complex targets.

More recently, we found that when display locations are serially cued, there is little or no detectable processing of the stimuli in these locations until attention is directed to them (Eriksen, Webb, \& Fournier, 1988). In these experiments displays essentially the same as those used in the present studies were employed. One display position was cued $50 \mathrm{msec}$ before display onset, a second display position was cued $50 \mathrm{msec}$ following display onset, and a third location was cued 50 msec later. On those trials in which a target did not occur in the first location, the stimulus letter in the second location was changed at the time it was cued. It could either be replaced by itself, be changed from Target 1 to Target 2 , or be changed from a noise letter to one of the two targets. Performance in terms of RT and errors was found to be the same for all three conditions. In a second experiment, the changing of the letter occupying the second cued location was delayed 20,40 , or $80 \mathrm{msec}$ following the onset of the cue. The results showed that changing the letter had no effect upon performance until the total time that the original letter had been available to the visual system exceeded $90 \mathrm{msec}$. Comparable results were obtained when the target did not occur in either the first or the second cued location and the changes of letters occurred in the third location.

Although we believe that a serial-search interpretation provides the most parsimonious account of the present results, particularly in view of the converging results of other experiments (Eriksen et al., 1988; Eriksen \& Yeh, 1985; Jonides, 1980, 1983), we recognize that a parallelprocessing account cannot be unequivocally ruled out. One of the most vexing problems in attentional research is the apparent ability of human subjects to adopt either a serialor a parallel-search strategy, depending upon the task. As yet, we have no definitive criteria for specifying the tasks or circumstances that determine which of these options is chosen.

A final comment is in order concerning the relation of the present experiments to a body of research that has shown the role of gestalt organizing principles on visual attentional selection (e.g., Banks \& Prinzmetal, 1976; Bartram, 1978; Kahneman \& Henik, 1981). The results of these studies clearly show that attention is object oriented. In the absence of location cues or other directive cues, attention is directed to stimuli that comprise good figures or are segregated in the visual field by other gestalt organizing principles. Although these organizing processes are probably preattentive, they determine where attentional resources are concentrated.

The effects of gestalt organizations are only tangentially relevant to our present concerns regarding the effects of spatial separation and interposition of noise between positions to be attended in the visual field. Even if a complex visual display is segregated or organized by gestalt forces, the question would still remain as to the effects of separation and interposition of noise within these segregated areas when a specific target must be searched for. Like location cues or precues, gestalt principles may determine which areas of the display are searched first, but spatial distance and interposition of noise are still largely separate variables.

\section{REFERENCES}

Banks, W. P., \& Prinzmetal, W. (1976). Configurational effects in visual information processing. Perception \& Psychophysics, 19, 361-367.

Bartram, D. (1978). Post-iconic visual storage: Chunking in the reproduction of briefly displayed visual patterns. Cognitive Psychol$o g y, 10,324-355$.

Colegate, R., Hoffman, J. E., Eriksen, C. W. (1973). Selective encoding from multielement visual displays. Perception \& Psychophysics, 14, 217-224.

CrassinI, B. (1986). On the spatial distribution of visual attention. Journal of Experimental Psychology: Human Perception \& Performance, 12, 380-382.

DUNCAN, J. (1980). The locus of interference in the perception of simultaneous stimuli. Psychological Review, 87, 272-300.

ERIKSEN, C. W., Hofrman, J. E. (1972). Some characteristics of selective attention in visual perception determined by vocal reaction time. Perception \& Psychophysics, 11, 169-171.

ErIKsen, C. W., Hoffman, J. E. (1973). The extent of processing of noise elements during selective encoding from visual displays. Perception \& Psychophysics, 14, 155-160.

ERIKSEN, C. W., \& MURPHY, T. (1987). Movement of the attentional focus across the visual field: A critical look at the evidence. Perception \& Psychophysics, 42, 299-305.

ERIKSEN, C. W., \& SPENCER, T. (1969). Rate of information processing in visual perception: Some results and methodological considerations. Journal of Experimental Psychology Monograph, 79(Pt. 2), $1-16$.

ERIKSEN, C. W., \& ST. JAMES, J. D. (1986). Visual attention within and around the field of focal attention: A zoom lens model. Perception \& Psychophysics, 40, 225-240.

Eriksen, C. W., Webe, J. M., \& Fournier, L. (1988). How much processing do non-attended stimuli receive? Not much. Manuscript in preparation.

ERIKSEN, C. W., YEH, Y. (1985). Allocation of attention in the visual field. Journal of Experimental Psychology: Human Perception \& Performance, 11, 583-597.

GARDNER, G. T. (1973). Evidence for independent parallel channels in tachistoscopic perception. Cognitive Psychology, 4, 130-155.

Hofrman, J. E. (1979). A two-stage model of visual search. Perception \& Psychophysics, 25, 319-327. 
JoNides, J. (1980). Toward a model of the mind's eye. Canadian Journal of Psychology, 34, 103-112.

JoNIDES, J. (1983). Further toward a model of the mind's eye's movement. Bulletin of the Psychonomic Society, 21, 247-250.

Kahneman, D., \& HeNik, A. (1981). Perceptual organization and attention. In M. Kubovy \& J. R. Pomerantz (Eds.), Perceptual organization. Hillsdale, NJ: Erlbaum.

KINCHLA, R. A. (1974). Detecting target elements in multi-element arrays: A confusability model. Perception \& Psychophysics, 15, 149-158.

LABERGE, D. (1983). Spatial extent of attention to letters in words. Journal of Experimental Psychology: Human Perception \& Performance, 9, 371-379.

MuRPhy, T. D., \& ERIKSEN, C. W. (1987). Temporal changes in the distribution of attention in the visual field in response to precues. Perception \& Psychophysics, 42, 576-586.

Podgorny, P., \& ShePARd, R. N. (1983). Distribution of visual attention over space. Journal of Experimental Psychology: Human Perception \& Performance, 9, 380-393.

Remington, R., \& Pierce, L. (1984). Moving attention: Evidence for time-invariant shifts of visual selective attention. Perception \& Psychophysics, 35, 393-399.

SAGI, D., \& JULESZ, B. (1985). Fast noninertial shifts of attention. Spatial Vision, 1, 141-149.

SCHNEIDER, W., \& SHiffrin, R. M. (1977). Controlled and automatic human information processing: I. Detection, search and attention. Psychological Review, 84, 1-66.

Shaw, M. L. (1978). A capacity allocation model for reaction time. Journal of Experimental Psychology: Human Perception \& Performance, 4, 586-598.
Shaw, M. L., \& Shaw, P. (1977). Optimal allocation of cognitive resources to spatial locations. Journal of Experimental Psychology: Human Perception \& Performance, 3, 201-211.

ShePard, R. N., \& Podgorny, P. (1986). Spatial factors in visual attention: A reply to Crassini. Joumal of Experimental Psychology: Human Perception \& Performance, 12, 383-387.

Shiffrin, R. M., \& GARDNER, G. T. (1972). Visual processing capacity and attentional control. Journal of Experimental Psychology, 93, 72-82.

Shulman, G. L., Remington, R. W., \& Mclean, J. P. (1979). Moving attention through visual space. Journal of Experimental Psychology: Human Perception \& Performance, 5, 522-526.

Townsend, J. T. (1971). A note on the identifiability of parallel and serial processes. Perception \& Psychophysics, 10, 161-163.

Treisman, A., Gelade, G. (1980). A feature integration theory of attention. Cognitive Psychology, 12, 97-136.

TSAL, Y. (1983). Movements of attention across the visual field. Journal of Experimental Psychology: Human Perception \& Performance, 9, 523-530.

\section{NOTE}

1. The error rates for the simultaneous-cue condition are rather high for experiments in which RT is the principal dependent variable. This resulted from our efforts to avoid possible ceiling effects in the precue condition. Display exposure duration (50 msec) was set so as to obtain an error rate of between $5 \%$ and $10 \%$ with the precue.

(Manuscript received May 18, 1988; revision accepted for publication August 19, 1988.) 